\title{
Correspondence
}

\section{Hemifacial Spasm}

To the Editor:

Ronen, Donat and Hill, ' in their discussion in the case of a child with hemifacial spasm, state that this disorder may be produced by aberrant regeneration of the facial nerve after injury. Same notion has been traditionally held to explain the post-facial palsy synkinesis and other phenomena. However, the weight of the current evidence is against such a mechanism in both conditions, which are clinically and physiologically identical. Although the authors refer to the elegant neurophysiological studies of Nielsen ${ }^{2.3}$ in hemifacial spasm, they fail to make any reference to ephaptic transmission, so fervently advanced by Nielsen, as the underlying mechanism of hemifacial spasm. I proposed the same for post-facial palsy phenomena in 1975 and argued for clinical and physiological identity of these two disorders affecting the facial nerve. ${ }^{4}$ The weight of the evidence is such now that the notion of aberrant facial nerve degeneration for both hemifacial spasm and post-facial palsy phenomena should be discarded in favour of ephaptic transmission. This same mechanism can be advanced just as well as for phenomena observed after other cranial palsies, (e.g., 3rd nerve palsy).

Kamal Sadjadpour, M.D. Department of Neurosciences Midland Hospital Center Midland, Michigan 48670 U.S.A.

1. Ronen GM, Donat JR, Hill A. Hemifacial spasm in childhood. Can J Neuro Sci 1986; 13: 342-343.

2. Nielsen VK. Pathophysiology of hemifacial spasm: 1. Ephaptic transmission and ectopic excitation. Neurology 1984;34:418-426.

3. Nielsen VK, Janeha PJ. Pathophysiology of hemifacial spasm: III. Effects of facial nerve decompression. Neurology 1984; 34: 891-897.

4. Sadjadpour, K. Post facial palsy phenomena: Faulty nerve regeneration or ephaptic transmission. Brain Research 1975; 95: 403-406. artificial synapses that facilitate ephaptic transmission between nerve fibers. The other hypothesis advocates altered facial motor neuron firing as the cause of HFS, triggered by antidromic impulses arising at the peripheral lesion. ${ }^{2.4-7}$ The notion of aberrant facial nerve regeneration has been disputed in favour of both of these pathogenetic mechanisms, ${ }^{1.2}$ but more recently even the notion of ephaptic transmission has been challenged as the sole mechanism in HFS..$^{4-7}$

Since our intention was only to draw attention to the occurrence of HFS in childhood, ${ }^{8}$ we did not deal extensively with the main pathogenetic hypotheses and the controversies involved, but in view of the mentioned studies by Møller and Janetta, ${ }^{4-7}$ we cannot join Dr. Sadjadpour in supporting the notion of ephaptic transmission as the leading hypothesis for this disorder.

Gabriel M. Ronen, M.D. Janeway Child Health Centre St. John's, Newfoundland Alan Hill, M.D., Ph.D. B.C.'s Children's Hospital Vancouver, British Columbia

1. Sadjadpour K. Post facial palsy phenomena: Faulty nerve regeneration or ephaptic transmission. Brain Research 1975; 95: 403-406.

2. Ferguson JH. Hemifacial spasm and the facial nucleus. Ann Neurol 1978; 4: 97-103.

3. Nielson VK. Pathophysiology of hemifacial spasm: I. Ephaptic transmission and ectopic excitation. Neurology 1984; 418-426.

4. Møller AR, Janetta PJ. On the origin of synkinesis in hemifacial spasm: Results of intracranial recordings. J Neurosurg 1984; 61: 569-576.

5. Møller AR, Janetta PJ. Hemifacial spasm: Results of electrophysiologic recording during microvascular decompression operations. Neurology 1985; 35: 969-974.

6. Møller AR, Janetta PJ. Microvascular decompression in hemifacial spasm: Intraoperative electrophysiological observations. Neurosurgery 1985; 16: 612-618.

7. Møller AR, Janetta PJ. Blink reflex in patients with hemifacial spasm: Observations during microvascular decompression operations. J Neurol Sc 1986; 72: 171-182.

8. Ronen GM, Donat JR, Hill A. Hemifacial spasm in childhood. Can J Neurol Sci 1986; 13: 342-343.

\section{Authors' Reply}

Two types of hemifacial spasm (HFS) are recognized: cryptogenic, which arises without previous known injury to the facial nerve and is usually caused by compression of the root entry zone of the seventh nerve by blood vessels, and post paralytic, occurring most often after incomplete recovery from Bell's palsy or traumatically induced facial paresis. The two types are often clinically indistinguishable, except for the history of previous facial palsy in the latter. Of the three main hypothesis, one explains post-paralytic HFS on the basis of aberrant regeneration. The other two, ephaptic transmission and abnormal seventh motor nucleus firing, suggest a common pathophysiology for both types ${ }^{1,2}$ and are supported by results of recent investigations on patients with "cryptogenic" HFS. ${ }^{3-7}$

The hypothesis which is strongly supported by Dr. Sadjadpour, ${ }^{1.3}$ suggests that injury to the nerve results in formation of

\section{Multiple Sclerosis Presenting as Third Nerve Palsy}

\section{To the Editor:}

In the August 1986 issue of CJNS Uitti and Rajput' reported what was believed to be the first documented case of multiple sclerosis presenting as a third nerve palsy with pupillary dilatation. We describe here another such case.

Our patient is a 14-year-old girl who developed diplopia in March 1986. She was prescribed glasses and the diplopia disappeared. She noted diplopia again in July 1986 which persisted. Two weeks later she noted that her right pupil was dilated. Past history revealed an episode of numbness in the fingers of both hands lasting several weeks. On examination the right pupil 